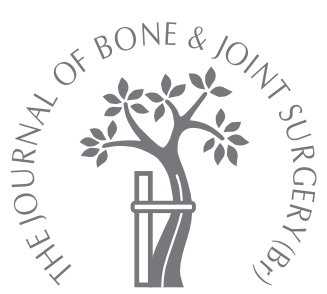

\author{
S. Nagoya, \\ M. Nagao, \\ J. Takada, \\ M. Kaya, \\ T. Iwasaki, \\ T. Yamashita \\ From Sapporo \\ Medical University, \\ Sapporo, Japan
}

- S. Nagoya, MD, PhD, Associate Professor M. Nagao, MD, PhD, Assistant Professor J. Takada, MD, PhD, Assistant Professor

M. Kaya, MD, PhD, Instructor

T. Iwasaki, MD, Orthopaedic Surgeon - T. Yamashita, MD, PhD, Professor and Chairman Department of Orthopedic Surgery

Sapporo Medical University, South 1 West 16 Chuo-Ku, Sapporo 060-8543, Japan.

Correspondence should be sent to Dr S. Nagoya; e-mail: nagoya@sapmed.ac.jp

C2006 British Editorial Society of Bone and Joint Surgery doi:10.1302/0301-620X.87B12. $16664 \$ 2.00$

$J$ Bone Joint Surg $[\mathrm{Br}]$ 2005;87-B:1627-30.

Received 22 April 2005

Accepted after revision

20 July 2005

\title{
Long-term results of rotational acetabular osteotomy for dysplasia of the hip in adult ambulatory patients with cerebral palsy
}

\author{
We performed rotational acetabular osteotomy in order to treat dysplasia of the hip in five \\ ambulatory adults with cerebral palsy. There was one man and four women, with a mean \\ age of 21 years (16 to 27) who were followed up for a mean of 12 years and two months. \\ The mean Sharp angle improved from $52^{\circ}$ to $43^{\circ}$, the mean acetabular index from $30.2^{\circ}$ to \\ $2.8^{\circ}$, the mean centre-edge angle from $-5.6^{\circ}$ to $29.2^{\circ}$, and the mean acetabular head index \\ from 49.2 to 88.2. There was no progression of joint degeneration and relief from pain was \\ maintained.
}

Our results suggest that rotational acetabular osteotomy is a valuable option for the treatment of acetabular dysplasia in adults with cerebral palsy who have incapacitating pain in the hip.

Acetabular dysplasia or subluxation of the hip as a sequel to cerebral palsy has been well documented. $^{1,2}$ Adult ambulatory patients with some paralysis because of cerebral palsy may develop a dysplastic hip ${ }^{3}$ and degenerative changes may occur at a relatively early stage. Operative procedures to improve articular congruency, and to achieve adequate acetabular cover may relieve pain and protect against degenerative change in the dysplastic hip. ${ }^{4-7}$

In immature patients with cerebral palsy, several types of osteotomy ${ }^{8-11}$ have been used to prevent dislocation of the femoral head and developmental dysplasia of the hip. Reports are also available on corrective osteotomy performed in adult ambulatory patients with cerebral palsy. However, there have been no studies to date on the long-term follow-up for acetabular osteotomy. In addition, it is not known whether degenerative change occurs in the hips of patients with cerebral palsy. Since 1984, we have used rotational acetabular osteotomy to treat osteoarthritis (OA) and acetabular dysplasia in 447 adult patients. Of these there were five skeletally-mature patients with cerebral palsy. Our aim, therefore, was to review our experience with this osteotomy and to report its long-term clinical results in adult ambulatory patients with cerebral palsy.

\section{Patients and Methods}

We performed rotational acetabular osteotomy on five consecutive adult ambulatory patients with cerebral palsy who also had ace- tabular dysplasia, or OA secondary to acetabular dysplasia. There was one man and four women, with a mean age of 21 years at operation (16 to 27 ). Using the Tönnis grading system for $\mathrm{OA}^{12}$ three patients were graded as 0 (before degenerative change), one as grade I and one as grade II. No patient with grade III OA was included. Four patients presented with spastic-type diplegia and one was athetoid. Flaccid-type cerebral palsy was not found in this series. All the patients could walk with a scissors gait and all but the one patient with athetotic-type cerebral palsy were unable to stand on one leg. In three patients, the contralateral hip had dislocated spontaneously. In one patient, there were signs of early $\mathrm{OA}$, and in one it was normal.

The operative indications for acetabular osteotomy were a centre-edge (CE) angle of Wiberg and Sweden ${ }^{13}$ of less than $10^{\circ}$ and substantial, progressive pain in the hip combined with radiographs which showed improvement in congruency of the hip in maximum abduction, and a spherical configuration of the femoral head. These patients were able to walk with or without crutches. Patients who were either bedridden or used a wheelchair for transfer were excluded from the study. The mean post-operative follow-up was 12 years and two months (10 to 14 years and two months).

Operative technique. With the patient in the lateral decubitus position, a modified Ollier's skin incision was used to obtain a wide view of 


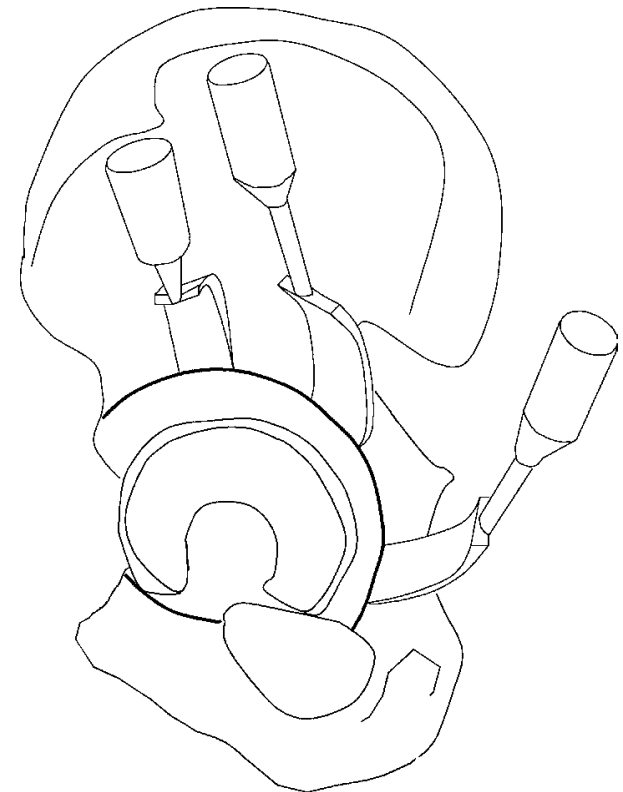

Fig. 1a

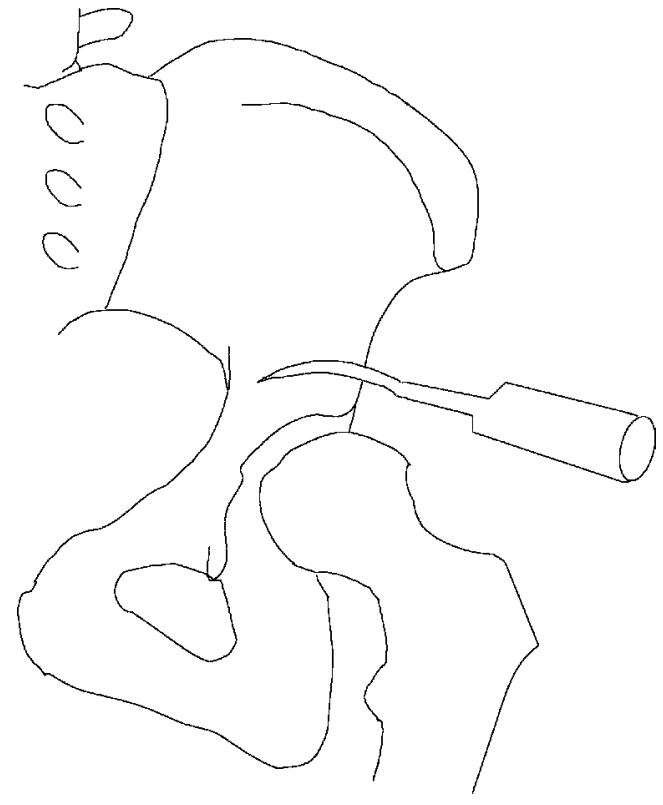

Fig. 1b

Diagrams showing a) a lateral view of the rotational acetabular osteotomy for a dysplastic hip (the thick, solid line indicates the osteotomy) and b) an anteroposterior view.

the lateral aspect of the hip, which was then exposed through a transtrochanteric approach. ${ }^{14}$ The skin incision began $1 \mathrm{~cm}$ distal and lateral to the anterosuperior iliac spine and curved distally and posteriorly over the lateral aspect of the greater trochanter and then proximally to a point $5 \mathrm{~cm}$ proximal to the base of the greater trochanter. The latter was then osteotomised and the capsule of the hip was exposed. This circumferential dissection was continued in order to expose approximately $2 \mathrm{~cm}$ of the innominate bone. This approach made it possible to identify the intended point for the acetabular osteotomy. Initially, a conventional osteotomy was used to penetrate the cortex of the pelvis and then a periacetabular spherical osteotomy was begun superolaterally and anterosuperiorly and the inner wall of the pelvis was penetrated using a special, curved osteotome. Posteriorly, the line of the osteotomy ran through the midpoint between the acetabular edge and the greater sciatic notch to the sulcus between the posterior acetabular edge and the ischial tuberosity. The osteotome was inserted anteriorly in order to divide the posterosuperior and posteroinferior parts of the acetabulum (Fig. 1) while the iliopubic eminence was osteotomised anteroinferiorly. The osteotomised acetabulum was then rotated laterally (Fig. 2) and held by two or three nonthreaded 2.4-mm Kirschner wires. The osteotomised greater trochanter was then re-attached in its original position by an $\mathrm{AO}$ cancellous screw. An additional adductor release was used in one patient with severe adductor stiffness. Post-operatively, the patients had bed rest for one or two weeks, partial weight-bearing was started at six weeks and full weight-bearing three months after surgery.

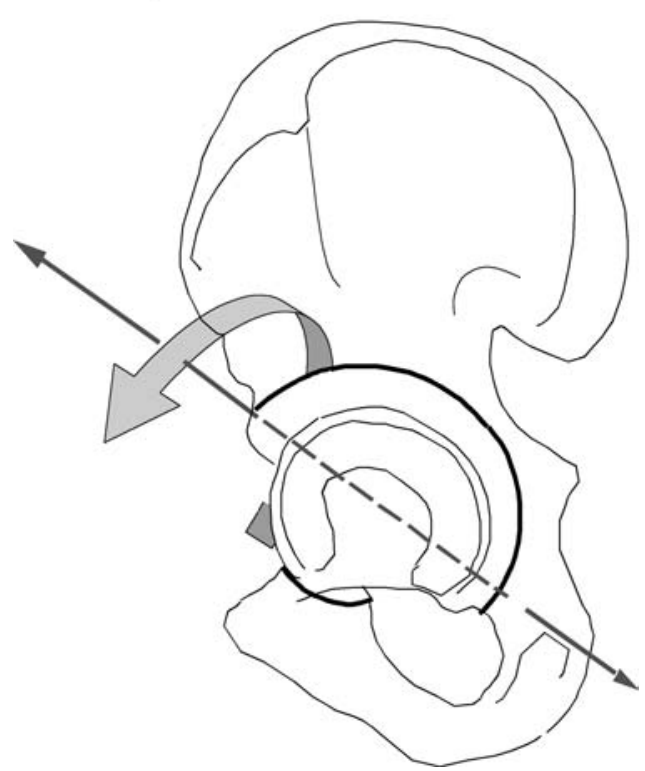

Fig. 2

Diagram showing the rotational direction of the osteotomised acetabulum.

Evaluation. The Sharp angle, ${ }^{15}$ acetabular index,${ }^{16} \mathrm{CE}$ angle ${ }^{13}$ and acetabular head index ${ }^{17}$ were measured from radiographs before and after operation and at the latest followup (Fig. 3). Each radiograph was also evaluated for the grade of OA according to Tönnis. ${ }^{12}$ The Merle d'Aubigné and Postel score ${ }^{18}$ and complications were also recorded 


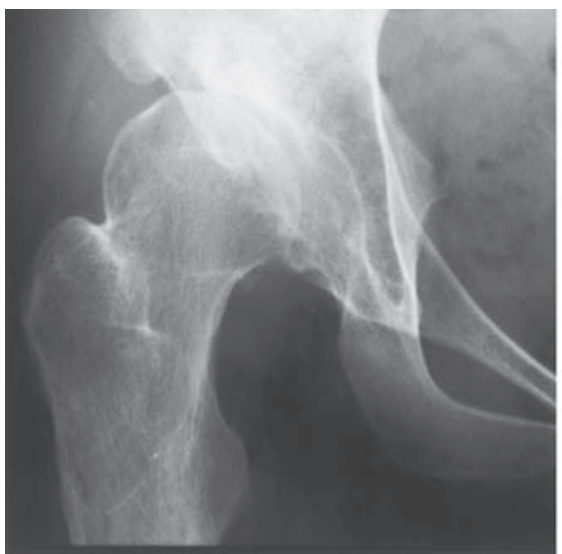

Fig. 3a

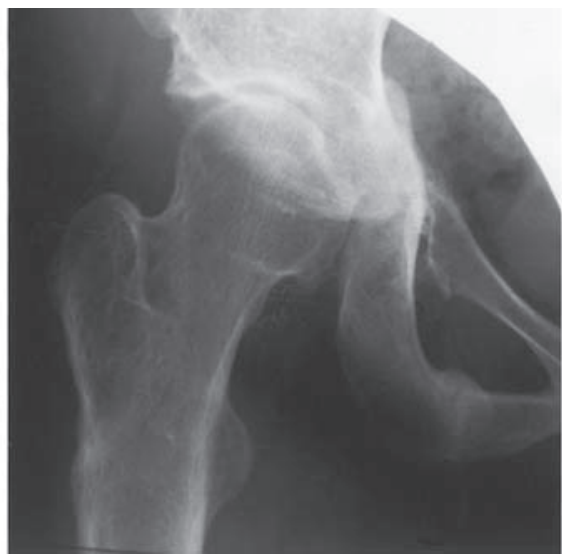

Fig. 3b

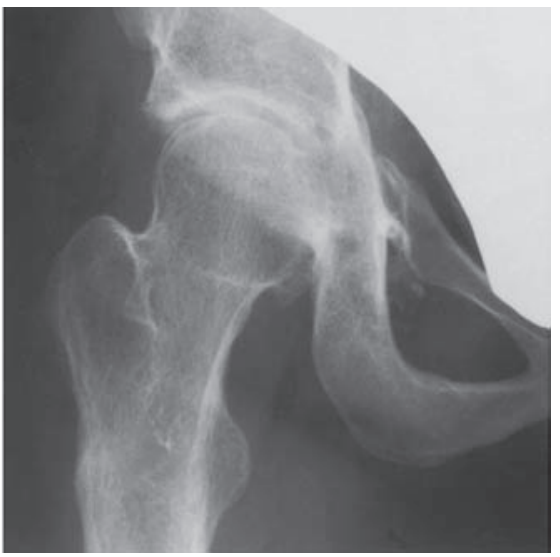

Fig. 3c

Radiographs of the right hip showing a) grade II osteoarthritis secondary to acetabular dysplasia, b) sufficient coverage of the acetabulum five years after operation post-operatively and c) no progression of degeneration ten years after operation.

Table I. Details of the results in the five patients

\begin{tabular}{|c|c|c|c|c|c|c|c|c|}
\hline \multirow[b]{2}{*}{ Cases } & \multicolumn{2}{|l|}{ Sharp angle $\left({ }^{\circ}\right)$} & \multicolumn{2}{|c|}{ Acetabular index angle $\left({ }^{\circ}\right)$} & \multicolumn{2}{|c|}{ Centre-edge angle $\left({ }^{\circ}\right)$} & \multicolumn{2}{|c|}{ Acetabular head index } \\
\hline & Pre-operative & Post-operative & Pre-operative & Post-operative & Pre-operative & Post-operative & Pre-operative & Post-operative \\
\hline 1 & 52 & 38 & 37 & -10 & -6 & 37 & 47 & 98 \\
\hline 2 & 58 & 50 & 31 & 21 & -6 & 18 & 49 & 80 \\
\hline 3 & 54 & 45 & 32 & 0 & -15 & 28 & 52 & 89 \\
\hline 4 & 48 & 39 & 18 & 3 & 8 & 32 & 56 & 86 \\
\hline 5 & 48 & 43 & 33 & 0 & -9 & 31 & 42 & 88 \\
\hline Mean & 52 & 43 & 30.2 & 2.8 & -5.6 & 29.2 & 49.2 & 88.2 \\
\hline
\end{tabular}

pre-operatively at five years after operation and at the final follow-up.

\section{Results}

The mean Sharp angle of $52^{\circ}$ pre-operatively improved to $43^{\circ}$ post-operatively. The mean pre-operative acetabular index angle was $30.2^{\circ}$ which improved to $2.8^{\circ}$ after operation and the mean CE angle from $-5.6^{\circ}$ pre-operatively to $29.2^{\circ}$ after operation. The mean acetabular head index improved from 49.2 to 88.2 post-operatively. These results indicate that adequate acetabular cover was achieved (Table I).

At the final follow-up, although radiography showed osteosclerotic change in the acetabular subchondral bone in one patient whose hip had been classified as having OA of grade II at the time of surgery, no progression of OA was seen in the remaining patients.

The mean Merle d'Aubigné and Postel ${ }^{18}$ score of 12.4 points pre-operatively, rose to 16.2 points five years after surgery. However, it had deteriorated to a mean of 15.4 at the time of the final follow-up, more than ten years after operation. The mean score for walking ability, 3.6 points pre-operatively improved to 4.6 points at five years after operation, but also deteriorated to 3.8 points at follow-up at ten years. The mean pain score of 2.8 points pre-operatively improved to 6 points in all patients post-operatively and was maintained at this level for more than ten years after surgery. Complications, including intra-operative fracture, deep infection, avascular necrosis of the osteotomised acetabulum and symptomatic thromboembolic disease, were not seen.

\section{Discussion}

Techniques such as soft-tissue release, varus osteotomy and acetabuloplasty have been used to treat acetabular dysplasia or developmental dislocation of the hip in order to optimise the gait of children with cerebral palsy. ${ }^{8-11}$ In addition, adult acetabular dysplasia should be treated in order to prevent $\mathrm{OA}$ of the hip because the osteoarthritic process may take decades to appear. ${ }^{19}$ Although the clinical results of periacetabular osteotomy for the treatment of neurogenic acetabular dysplasia have been reported by MacDonald, Hersche and Ganz, ${ }^{20}$ the long-term clinical results of acetabular osteotomy for the treatment of acetabular dysplasia in adult ambulatory patients with cerebral palsy have not been reported. MacDonald et $\mathrm{al}^{20}{ }^{20}$ reported that the Bernese periacetabular osteotomy could be used successfully to treat neurogenic acetabular dysplasia. However, in contrast to their report which included flaccid paralytic hips, our patients had only spastic paralysis. They also reported that one patient developed femoroacetabular 
impingement, but post-operative radiographs in our series did not show retroversion of the rotated acetabulum. ${ }^{20}$ Buckley et $\mathrm{al}^{1}$ reported that the acetabulum in patients with cerebral palsy had global bone deficiency, anteriorly, superiorly and posteriorly. In our series the acetabulum was rotated laterally in order to achieve lateral acetabular cover and to avoid excessive anterior cover.

There have been several reports describing the long-term outcome of rotational acetabular osteotomy. ${ }^{5-7}$ In these, acetabular cover by peri-acetabular osteotomy conferred favourable results with prevention of osteoarthritic progression in patients with early-stage disease secondary to acetabular dysplasia. We performed rotational osteotomy for acetabular dysplasia in adult ambulatory patients with cerebral palsy, and followed them up clinically for more than ten years. At five years no patient complained of pain in the hip, and this was maintained for more than ten years after surgery. Furthermore, the radiological findings did not show any progression of $\mathrm{OA}$ in the hip after rotational acetabular osteotomy.

In patients with cerebral palsy, pain in the hip may exacerbate the muscular spasticity and contracture capable of inducing degenerative changes in the joint. It is still unclear whether an improvement in acetabular cover influences muscle imbalance, and contributes to relief from pain in the long-term.

This operation has many advantages, with its easy exposure of the lateral pelvis and the performance of a spherical osteotomy, compared with the operative techniques previously described by Ganz et al. ${ }^{21}$ The position of the patient does not need to be changed during surgery. The lateral decubitus position is used, and anterior and lateral cover of the acetabulum can be achieved by simple lateral rotation of the spherically-osteotomised acetabulum. Because the medial aspect of the osteotomy can be seen by rotation and retraction of the osteotomised acetabulum, medialisation of the centre of the hip also can be obtained by trimming the medial cancellous bone of the rotated acetabulum. The laterally-rotated acetabulum also makes the weight-bearing surface more horizontal, which can decrease the shearing forces through the hip.

Because contracture of the adductor muscles and acetabular dysplasia combine to force the femoral head superolaterally in patients with cerebral palsy, degenerative change is more likely to occur than in patients without cerebral palsy. ${ }^{22}$ Our results suggest that if sufficient acetabular cover is obtained by rotational osteotomy, progression of degenerative disease can be prevented for more than ten years.

On the basis of our results, we conclude that rotational acetabular osteotomy is indicated for adults with cerebral palsy when they are able to walk with or without crutches, complain of substantial pain in the hip, present with a CE angle of less than $10^{\circ}$ and are likely to have sufficient acetabular cover after surgery. Rotational acetabular osteotomy is a valuable option for treating acetabular dysplasia in adult patients with cerebral palsy who have incapacitating pain in the hip.

No benefits in any form have been received or will be received from a commercial party related directly or indirectly to the subject of this article.

\section{References}

1. Buckley SL, Sponseller PD, Magid D. The acetabulum in congenital and neuromuscular hip instability. J Pediatr Orthop 1991;11:489-501.

2. Kim HT, Wenger DR. Location of acetabular deficiency and associated hip dislocation in neuromuscular hip dysplasia: three-dimensional computed tomographic analysis. J Pediatr Orthop 1997;17:143-51

3. Howard CB, McKibbin B, Williams LA, Mackie I. Factors affecting the incidence of hip dislocation in cerebral palsy. J Bone Joint Surg [Br] 1985;67-B:530-2.

4. Hasegawa Y, Iwase T, Kitamura S, et al. Eccentric rotational acetabular osteotomy for acetabular dysplasia: follow-up of one hundred and thirty-two hips for five to ten years. J Bone Joint Surg [Am] 2002;84-A:404-10.

5. Nozawa M, Shitoto K, Matsuda K, Maezawa K, Kurosawa H. Rotational acetabular osteotomy for acetabular dysplasia. J Bone Joint Surg [Br]2002;84-B:59-65.

6. Nakamura S, Ninomiya S, Takatori Y, Morimoto S, Umeyama T. Long-term outcome of rotational acetabular osteotomy: 145 hips followed for 10-23 years. Acta Orthop Scand 1998;69:259-65.

7. Millis MB, Murphy SB, Poss R. Osteotomies about the hip for the prevention and treatment of osteoarthritis. J Bone Joint Surg [Am] 1995;77-A:626-47.

8. McNerney NP, Mubarak SJ, Wenger DR. One-stage correction of the dysplastic hip in cerebral palsy with the San Diego acetabuloplasty: result and complications in 104 hips. J Pediatr Orthop 2000:20:93-103.

9. Dietz FR, Knutson LM. Chiari pelvic osteotomy in cerebral palsy. J Pediatr Orthop 1995;15:372-80.

10. Shea KG, Coleman SS, Carroll K, Stevens P. Pemberton pericapsular osteotomy to treat a dysplastic hip in cerebral palsy. J Bone Joint Surg [Am]1997;79-A:1342-51.

11. Gordon JE, Capelli AM, Strecker WB, Delgado ED, Schoenecker PL. Pemberton pelvic osteotomy and varus rotational osteotomy in the treatment of acetabular dysplasia in patients who have static encephalopathy. J Bone Joint Surg [Am] 1996; 78-A:1863-71.

12. Tönnis D. Normal values of the hip joint for the evaluation of $X$-rays in children and adults. Clin Orthop 1976;119:39-47.

13. Wiberg G, Sweden L. Shelf operation in congenital dysplasia of the acetabulum and in subluxation and dislocation of the hip. J Bone Joint Surg [Am] 1953;35-A: $65-80$

14. Senegas J, Liorzou G, Yates $\mathbf{M}$. Complex acetabular fractures: a transtrochanteric lateral surgical approach. Clin Orthop 1980;151:107-14.

15. Sharp IK. Acetabular dysplasia: the acetabular angle. J Bone Joint Surg [Br] 1961; 43-B:268-72

16. Massie WK, Howorth B. Congenital dislocation of the hip. Part I: method of grading result. J Bone Joint Surg [Am] 1950;32-A:519-31.

17. Heyman $\mathbf{C H}$, Herndon $\mathbf{C H}$. Legg-Perthes disease: a method for the measurement of the roentgenographic results. J Bone Joint Surg [Am]1950;32-A:767-78.

18. Merle d'Aubigne R, Postel M. Functional results of hip arthroplasty with acrylic prosthesis. J Bone Joint Surg [Am] 1954;36-A:451-75.

19. Cooperman DR, Wallensten R, Stulberg SD. Acetabular dysplasia in the adult. Clin Orthop 1983;175:79-85.

20. MacDonald SJ, Hersche 0, Ganz R. Periacetabular osteotomy in the treatment of neurogenic acetabular dysplasia. J Bone Joint Surg [Br] 1999;81-B:975-8.

21. Ganz R, Klause $\mathbf{K}$, Winh TS, Mast JW. A new periacetabular osteotomy for the treatment of hip dysplasia: technique and preliminary results. Clin Orthop 1988;232: 26-36.

22. Bagg MR, Farber J, Miller F. Long-term follow-up of hip subluxation in cerebral palsy patients. J Pediatr Orthop 1993:13:32-6. 